\section{Effects of consanguineous marriage on reproductive outcome in an Arab community in Israel}

Lutfi Jaber, Paul Merlob, Reuben Gabriel, Mordechai Shohat
Department of Pediatrics, Tulene Medical Center, Tulene University, New Orleans, USA, The Bridge to Peace Paediatric Centre, Taibe, and the Unit of Community

Paediatrics, Schneider Children's Medical Centre of Israel, Petah Tiqva, Israel

L Jaber

Department of Neonatology, Rabin Medical Centre, Beilinson Campus, Petah Tiqva, Sackler Faculty of Medicine, Tel Aviv University, Israel

P Merlob

Department of Biostatistics,

Rochester University, Rochester, NY, USA R Gabriel

Department of Medical Genetics, Rabin Medical Centre, Beilinson Campus, Petah Tiqva, Sackler Faculty of Medicine, Tel Aviv University, Israel

M Shohat

Correspondence to: Dr Jaber, The Bridge to Peace Paediatric Centre, Box 27, Taibe 40400, Israel.

Received 25 July 1996 Revised version accepted for publication 2 July 1997

\begin{abstract}
Intrafamilial marriage is favoured by the Arab community in Israel, almost all of whom live in villages populated by a few (<20) founding families. A previous study in Taibe, a large Arab village located 30 km from Tel Aviv, showed a significantly high malformation rate among infants of consanguineous parents. The present study examines the reproductive consequences of parental consanguinity in 610 families from the same village, selected retrospectively through infants routinely seen in the local well baby clinic. All mothers were interviewed with regard to previous pregnancy outcomes, including abortions, stillbirths, and neonatal or infant deaths, as well as the degree of consanguinity. In addition, we analysed the anthropometric measurements of the probands. The incidence of infant deaths was significantly higher in the inbred group ( $p<0.001)$. No significant increase in fetal loss between the inbred and outbred groups was observed. There were no differences in anthropometric features, except for a lower birth weight in the consanguineous group $(p<0.035)$. This study, combined with our previous studies of the same population, indicates a prominent public health problem associated with consanguineous marriage in the Arab community and a need for specific genetic counselling.

$(\mathcal{F}$ Med Genet 1997;34:1000-1002)
\end{abstract}

Keywords: inbreeding; parental consanguinity; consanguineous marriages; reproductive outcome

The biological effects of consanguineous marriages have been studied extensively in almost all populations throughout the world. ${ }^{1-26} \mathrm{Sev}-$ eral studies in Israel have shown marked parental consanguinity in the non-Jewish community, approaching $40-50 \%$ in the Muslim and Druze groups. ${ }^{13-5} 79$ The inbreeding coefficient was higher in rural areas and more than half of these marriages were between first cousins. It was generally believed that inbreeding, by increasing mortality and morbidity, has detrimental effects on reproductive outcome. ${ }^{2511-1323}$ However, studies conducted in Brazil and Japan have shown only a moderate to slight impact, ${ }^{1525}$ and a prospective study on large numbers of couples has shown no detrimental effect of inbreeding on reproduction and mortality. ${ }^{3}$ It was suggested in the latter study that the adverse consequences of inbreeding might have been eliminated by the eradication of deleterious recessive genes in earlier generations. Unfortunately, though, not all published studies have taken into account possible sources of bias, mainly socioeconomic status and other confounding factors. $^{23} 5^{10-13} 1523$

In a previous prospective study, we examined the incidence of major congenital malformations in a homogeneous socioeconomic group in Taibe, one of the largest Arab villages in Israel. ${ }^{7}$

Higher rates of major congenital malformations were observed among the offspring of related parents, specifically, $15.8 \%, 15.1 \%$, and $8.7 \%$ among children of first cousins, distant relatives, and unrelated parents, respectively. The purpose of the present work was to evaluate retrospectively the same families that participated in our earlier study ${ }^{7}$ to determine the effect of parental consanguinity on fetal growth (anthropometric measurements at birth) and outcome until the end of the first year of life (rates of abortions, stillbirths, neonatal deaths, and infant deaths).

\section{Materials and methods}

We re-evaluated the same population described in our previous study of $1992 .^{7}$ All participants were residents of Taibe, one of the largest and most developed Arab villages in Israel. The population of Taibe is made up of 20 extended families, all of whom are Moslem. Only a few intervillage marriages have taken place since its founding.

In the previous study, 610 families were randomly ascertained through the infants (index cases) routinely screened in the local well baby clinic. A known consanguineous mating was apparent in $236(38.7 \%)$; most were first cousin marriages. Only $374(61.3 \%)$ were unrelated type marriages. The socioeconomic status of the families was defined according to family properties and yearly income, and classified as high, average, and low. No significant difference was found between these parental groups in either number of offspring or socioeconomic status, as was detailed in tables 1 and 2 of the previous study.

All additional information necessary for the present study was collected from the same 610 families under the same conditions. The mothers were personally and extensively interviewed with respect to age (their own and their spouse's) 
Table 1 Prenatal death according to degree of parental consanguinity

\begin{tabular}{llllllc}
\hline $\begin{array}{l}\text { Degree of } \\
\text { consanguinity }\end{array}$ & $\begin{array}{l}\text { No of } \\
\text { families }\end{array}$ & $\begin{array}{l}\text { No of } \\
\text { pregnancies }\end{array}$ & $\begin{array}{l}\text { Abortions } \\
(\%)\end{array}$ & $\begin{array}{l}\text { No of } \\
\text { children born }\end{array}$ & $\begin{array}{l}\text { Stillbirths } \\
(\%)\end{array}$ & $\begin{array}{l}\text { Total prenatal } \\
\text { losses (\%) }\end{array}$ \\
\hline First cousins & 170 & 479 & $91(19.0)$ & 388 & $6(1.5)$ & $97(20.3)$ \\
Distant relatives & 66 & 199 & $25(12.6)$ & 174 & $2(1.1)$ & $27(20.3)$ \\
Unrelated & 374 & 854 & $150(17.6)$ & 704 & $6(0.9)$ & $156(18.3)$ \\
p value & & & 0.11 & & 0.58 & 0.12 \\
\hline
\end{tabular}

Table 2 Neonatal and infant deaths according to degree of parental consanguinity

\begin{tabular}{lcccl}
\hline & \multicolumn{4}{l}{ Degree of consanguinity } \\
\cline { 2 - 5 } & First cousins & $\begin{array}{c}\text { Distant } \\
\text { relatives }\end{array}$ & Unrelated & Significant $(p)$ \\
\hline No of live births & 382 & 172 & 698 & \\
Neonatal deaths (\%) & $6(1.6)$ & $1(0.6)$ & $6(0.9)$ & NS \\
Cong malformation & 2 & 1 & 3 & \\
No malformation & 4 & 0 & 3 & NS \\
Infant deaths (\%) & $24(6.3)$ & 0 & $9(1.3)$ & $<0.001$ \\
Cong malformation & 17 & 0 & 1 & $<0.003$ \\
No malformation & 7 & 0 & 8 & $<0.001$ \\
Total wastage (\%) & $30(7.8)$ & $1(0.6)$ & $15(2.2)$ & 4 \\
Cong malformation & 19 & 1 & 4 & $<0.027$ \\
No malformation & 11 & 0 & 11 & \\
\hline
\end{tabular}

Table 3 Causes of neonatal and infant death among liveborn in the three groups according to parents' relationship

\begin{tabular}{llll}
\hline & $\begin{array}{l}\text { First } \\
\text { cousin } \\
(n=382)\end{array}$ & $\begin{array}{l}\text { Distant } \\
\text { relatives } \\
(n=172)\end{array}$ & $\begin{array}{l}\text { Unrelated } \\
(n=698)\end{array}$ \\
\hline $\begin{array}{l}\text { Congenital malformation } \\
\text { CNS }\end{array}$ & 19 & 1 & 4 \\
Microcephalus & $2^{\star}$ & & \\
Microcephalus+conv+cleft & $2 \dagger$ & & \\
palate & 1 & & \\
Hydrocephalus & 3 & & \\
Others (structural) & $5 \dagger$ & 1 & $1^{\star}$ \\
CHD & $2^{\star}$ & 1 & 2 \\
GIT & $1^{\star}$ & & 1 \\
Renal & & & \\
Muletal & 1 & & \\
CNS+CHD & 1 & & 4 \\
Renal+MR & 1 & & 4 \\
Metabolic & $5 \dagger$ & & 4 \\
Prematurity & 3 & & 3 \\
Unknown cause & 4 & & \\
No genetic cause & & & \\
\hline
\end{tabular}

^In one of them, history of a sib with a different major anomaly. tIncludes one set of similarly affected sibs.

CNS=central nervous system; $\mathrm{CHD}=$ congenital heart disease, $\mathrm{GIT}=$ gastrointestinal tract; $M R=$ mental retardation.

and the number of previous pregnancies, abortions, stillbirths, live births, neonatal deaths, and deaths of children before the end of the first year of life. Loss of the fetus up to 28 weeks of gestation was considered an abortion, after 28 weeks a stillbirth, and up to the end of the first year of life as infant death. The family pedigree and the intrafamilial relationship of the proband's parents were also obtained. The gestational age and anthropometric measurements of the probands were determined from

Table 4 Effect of consanguinity on mean birth weight, length, and head circumference among liveborn infants who survived one year

\begin{tabular}{llll}
\hline Degree of consanguinity & Birth weight $(g)$ & Length $(\mathrm{cm})$ & Head circumference \\
\hline First cousins $(\mathrm{n}=358)$ & 3112 (SD 620) & 49.85 (SD 2.65) & 34.50 (SD 1.61) \\
Distant relatives (n=172) & 3207 (SD 642) & 49.79 (SD 2.62) & 34.23 (SD 1.24) \\
Unrelated (n=689) & 3323 (SD 614) & $49.95($ SD 2.46) & 34.39 (SD 1.11) \\
F ratio* & 2.64 & 0.15 & 0.87 \\
p value & 0.035 & 0.86 & 0.41 \\
\hline
\end{tabular}

^Analysis of covariance of degree means adjusted for gestational age. the medical records of the neonatal department in all the liveborn infants surviving to 1 year of age.

For tabulation and analysis, the families were divided into consanguineous and nonconsanguineous marriages. The consanguineous group was then further subdivided into first cousin marriages and marriages between distant relatives. The association of wastage with parental consanguinity was analysed by the chi-square test and the association of congenital malformations with parental consanguinity by Fisher's exact test (two tailed). Mean differences in various anthropometric features between the groups were tested for significance by analysis of variance, after checking that the variance was the same. Analysis of the covariance of the anthropometric measures allowed adjustment for differences in gestational age.

\section{Results}

A total of 678 pregnancies was recorded in the consanguineous marriage group, 479 in the first cousins and 199 in the distant relatives, and 854 in the unrelated group. At the time of the study, the number of pregnancies per woman was higher in the consanguineous $(2.8-3)$ than in the non-consanguineous group (2.3).

The analysis of reproductive wastage showed no significant differences in frequency of abortions and stillbirths between the three groups (first cousins, distant relatives, unrelated) (table 1). This was also true of total prenatal losses (abortions + stillbirths). However, significant differences between the groups were found for infant death rates, including deaths during the first month and during the first year of life (table 2). The causes of death are shown in table 3. There was a significantly higher proportion of congenital malformations as the cause of neonatal death and total wastage in the group of first cousin marriages compared to the group of unrelated parents (table 2).

A positive history of congenital malformation (sibs of neonates or infants who died after birth) was found in five infants born to first cousin parents and in only two infants born to unrelated parents. In the former, the same malformation recurred in two sibs of two different families. Different malformations occurred in the other three cases born to first cousin parents, as well as in the two instances of congenital anomalies recorded in the unrelated parents group.

Table 4 shows the anthropometric features of surviving infants in the three groups. Analysis of variance indicated no significant difference in mean body length and head circumference. However, mean birth weight was significantly lower $(p<0.035)$ in the infants born to first cousin parents compared to those born to distantly related and to unrelated parents. The adjusted mean for offspring of first cousins was approximately $110 \mathrm{~g}$ less than that for offspring of unrelated parents. 


\section{Discussion}

Modernisation has had only a slight effect on lessening endogamy in the Arab community in Israel. The overall cross sectional proportion of marriages between relatives is $43 \%$, with first cousin matings being the most prevalent $(55 \%) .{ }^{79}$ In a previous study we showed that the prevalence of congenital malformations among offspring of related parents in this population is high $(15.1-15.8 \%)$.

In the present study we investigated the effect of consanguineous marriage on reproductive performance in terms of fetal growth, fetal loss, and infant death. We showed increased mortality during infancy among inbred offspring, but no significant difference in the rate of fetal loss (abortions and stillbirths) between the inbred and outbred groups. Of note is the possible bias that sterile and infertile women would not have attended the well baby clinic. Therefore, the lack of effect of consanguineous marriages on abortion and sterility should be regarded cautiously until investigated in women attending infertility clinics.

These results are in agreement with findings of other reports investigating the effect of inbreeding on mortality in consanguineous marriages. Postnatal mortality was found to be significantly and markedly higher among the conceptuses of consanguineous matings, in countries with a high rate of inbreeding (southern India and Sudan) ${ }^{16}{ }^{172021}$ as well as in developed countries (USA, France, and Japan $)^{22}$ but not among the Samaritans living in Israel and Jordan, ${ }^{19}$ who have a high proportion of consanguineous matings (27\% and $24 \%$ ). As in our findings, however, the Samaritans and several other peoples showed no effect of consanguinity on prenatal mortality. ${ }^{12-17}{ }^{20-21} \mathrm{We}$ suggest, therefore, that the alleged natural selection resulting from inbreeding does not operate prenatally. Published reports on the effects of consanguinity on fetal growth are conflicting. Such effects may be determined by genetic as well as environmental factors. The groups studied here were similar in socioeconomic status, with only marginal differences in mean birth weights of the offspring. Except for the study of Rao and Inbaraj, ${ }^{18}$ all publications reported findings similar to ours, with a decreased mean birth weight in offspring of consanguineous matings. ${ }^{51826}$ It seems that birth weight is the only anthropometric factor that is changed in consanguineous matings.

A significant number of health problems associated with intrafamilial marriage have been observed in the Israeli-Arab community, placing a heavy burden on people, families, society, and the health system. Until very recently, genetic disorders and congenital mal- formations in the Arab community in Israel were studied only incidentally, and the early investigations designed to clarify this issue have shown interesting and unexpected findings. ${ }^{14-9}$ Further studies on a nationwide basis are necessary.

Changing deep rooted social and religious customs is a long and painstaking process. In view of these and earlier results, we recommend the institution of such intensive preventive measures as genetic counselling, preconceptional multivitamin supplementation, and prenatal care in Arab communities in Israel.

1 Bashi J. Effects of inbreeding on cognitive performance. Nature 1977;266:440-2.

2 Bittles AH, Mason WM, Greene J, Rao NA. Reproductive behavior and health in consanguineous marriages. Science 1991;252:789-94.

3 Darlington CD. Cousin marriage and the evaluation of inbreeding system in man. Heredity 1973;14:297-331.

4 Freundlich E, Hino N. Consanguineous marriage among rural Arabs in Israel. Isr $\mathcal{f}$ Med Sci 1984;20:1035-8

5 Fried K, Davies AM. Some effects on the offspring of uncleniece marriage in a Moroccan Jewish community in Jerusalem. Am ₹ Hum Genet 1974;26:65-72.

6 Gev D, Roguin N, Freundlich E. Consanguinity and congenital heart disease in the rural Arab population in Northern Israel. Hum Hered 1986;36:213-17.

7 Jaber L, Merlob P, Shohat M. Marked parental consanguinity as a cause for increased major congenital malformation in an Israeli Arab community. Am f Med Genet 1992;44:16.

Jaber L, Shohat M. Cochlear deafness - a two locus disorder determined by mitochondrial and autosomal locus. $A m \mathcal{F}$ Med Genet 1992;29:81-6.

9 Jaber L, Bailey-Wilson JE, Haz-Hehia M, Hernandez J, Shohat $M$. Consanguineous matings in an Israeli-Arab community. Arch Pediatr Adolesc Med 1994;148:412-15

10 Klat $M$, Khoury $M$. Inbreeding and diseases: demographic genetic, and epidemiologic perspectives. Epidemiol Rev 1991;13:28-41.

11 Kulkarni ML, Kurian M. Consanguinity and its effect on fetal growth and development: a South Indian study. $\mathscr{F} \mathrm{Med}$ Genet 1990;27:348-52.

12 Magnus P, Berg K, Bierkedal T. Association of parental consanguinity with decreased birth weight and increased rate of early death and congenital malformations. Clin Gene 1985;28:335-42.

13 McCluer JW. Inbreeding and human fetal death. In: Porter I, Hook I, eds. Human embryonic and fetal death. New York: Academic Press, 1980:241-61.

14 Morton NE. The inheritance of human birth weight. Ann Hum Genet 1955;20:125-34.

15 Freire-Maia A, Stevenson C, Morton NE. Hybridity effect on mortality. Soc Biol 1974;21:232-4.

16 Rao PSS, Inbaraj SG. Inbreeding effects on human reproduction in Tamil Nadu region of southern India. Ann Hum

17 Rao PSS, Inbaraj SG. Inbreeding effects on fertility and sterility in southern India. $\mathcal{F}$ Med Genet 1979;16:24-31.

8 Rao PSS, Inbaraj SG. Inbreeding effect on fetal growth and development. F Med Genet 1980;17:27-33.

9 Roberts DF, Bonne B. Reproduction and inbreeding amon the Samaritans. Soc Biol 1973;20:64-70.

20 Reddy VR, Rao AP. Effects of parental consanguinity on fertility, mortality and morbidity among Pattusalis of Tirupati, South India. Hum Hered 1978;28:226-34.

21 Saha N, Hamad RE, Mohamed S. Inbreeding effects on reproductive outcome in Sudanese population. Hum Hered 1990;40:208-12.

22 Sanghvi LD. Inbreeding in India. Eugenics Quart 1966;13: $291-301$

23 Shami SA, Schmit LH, Bittles AH. Consanguinity related prenatal and postnatal mortality of populations of seven prenatal and postnatal mortality of populations of

24 Shohat $M$, Jaber L. Arthrogryposis in an Arab kindred with 33 affected individuals. Am 7 Hum Genet 1992;51:A1221. Shull WJ, Furusho T, Yamamanto M, et al. The effect of parental consanguinity and inbreeding in Hirado, Japan parental consanguinity and inbreeding in Hirado, Japan. 1970;9:294-315.

26 Sibert JR, Jadhav M, Inbaraj SG. Fetal growth and parental consanguinity. Arch Dis Child 1979;54:317-19. 